\title{
DÜBLIN
}

Technological University Dublin ARROW@TU Dublin

1999-01-01

\section{Square Planar Monopole Antenna}

\author{
Max Ammann \\ Technological University Dublin, max.ammann@tudublin.ie
}

Follow this and additional works at: https://arrow.tudublin.ie/engschececon

Part of the Electrical and Computer Engineering Commons

\section{Recommended Citation \\ This Conference Paper is brought to you for free and open access by the School of Electrical and Electronic Engineering at ARROW@TU Dublin. It has been accepted for inclusion in Conference papers by an authorized administrator of ARROW@TU Dublin. For more information, please contact arrow.admin@tudublin.ie, aisling.coyne@tudublin.ie,gerard.connolly@tudublin.ie.}

Ammann, M. (1999) Square planar monopole antenna. IEE National Conference on Antennas and Propagation, York, 31 March-1 April, 1999, doi:10.1109/NCAP.1999.788830 
SQUARE PLANAR MONOPOLE ANTENNA.

\author{
M. J. Ammann \\ Dublin Institute of Technology, Ireland
}

\title{
INTRODUCTION
}

A planar disc monopole antenna has been studied by Honda et al. in 1991 [1], who developed this antenna for the Japanese television band (90-770 $\mathrm{MHz}$ ). In 1992 he reported one which had a return loss greater than $10 \mathrm{~dB}$ for all of $\mathrm{S}, \mathrm{C}, \mathrm{X}$ and $\mathrm{Ku}$ bands, i.e. a 1:18 bandwidth. A model for determining the input impedance of a circular disc monopole based on the Method of Moments has been proposed by Hammoud et al. in 1993 [2]. The circular disc monopole has also been studied by Agrawall et al. in 1998 [3], who proposed a simple formula for predicting the frequency corresponding to the lower edge of the bandwidth.

A planar monopole may be realised by replacing the wire element of a conventional monopole with a planar element. In this case, the planar element which is square, is located above a groundplane and fed using an SMA connector as illustrated in Figure 1. The square monopole has a simple geometry and a smaller bandwidth compared to the circular disc monopole. However, it is still a broadband antenna with a typical impedance bandwidth of $75 \%$ at $S$ band.

\section{IMPEDANCE BANDWIDTH AND THE EFFECT OF FEEDGAP DISTANCE}

Measurements of return loss have been made for various sizes of square monopole on a $25 \mathrm{~cm}$ square copper groundplane. A brass planar element of thickness $0.5 \mathrm{~mm}$ was used. The bandwidth is dependent on the feed gap, $h$. The return loss for a $30 \mathrm{~mm}$ square monopole with feed gaps of $0.8,1.6$ and $2.5 \mathrm{~mm}$ is shown in Figure 2. From this it can be seen that a feed gap of $2.5 \mathrm{~mm}$ gives the optimum value of bandwidth for this element; increasing the gap further reduces the impedance bandwidth. The frequency corresponding to the lower edge of the bandwidth is fairly independent of the feed gap, $h$, but the upper frequency is heavily dependent on it. The impedance locus for this element with a $2.5 \mathrm{~mm}$ feedgap is shown in Figure 3.
The bandwidth was measured for seven values of dimension, $L$, of the square element and the maximum value was obtained by optimising the feedgap distance for each element. Square elements of size $25,30,35,40,45,50$ and $55 \mathrm{~mm}$ were used. The $10 \mathrm{~dB}$ return loss impedance bandwidth and the optimum feedgap distance is tabulated in Table 1.

TABLE 1 - Impedance bandwidth (10 dB return loss) for various square elements.

\begin{tabular}{|c|c|c|c|}
\hline $\begin{array}{c}\text { Square } \\
\text { size, } L, \\
(\mathrm{~mm})\end{array}$ & $\begin{array}{c}\text { Frequency } \\
\text { limits }(\mathrm{GHz})\end{array}$ & $\begin{array}{c}\text { Bandwidth } \\
(\mathrm{MHz})\end{array}$ & $\begin{array}{c}\text { Optimum } \\
\text { feedgap } \\
(\mathrm{mm})\end{array}$ \\
\hline 55 & $1.23-2.19$ & 960 & 3 \\
\hline 50 & $1.34-2.35$ & 1010 & 3 \\
\hline 45 & $1.44-2.59$ & 1150 & 2.5 \\
\hline 40 & $1.59-2.96$ & 1370 & 2.5 \\
\hline 35 & $1.86-3.53$ & 1670 & 2.5 \\
\hline 30 & $1.98-4.05$ & 2090 & 2.5 \\
\hline 25 & $2.38-5.20$ & 2820 & 2.5 \\
\hline
\end{tabular}

\section{CALCULATION OF THE LOWER EDGE FREQUENCY}

For a cylindrical stub antenna on a large groundplane, the stub length for the first resonance [4] is given by

$$
L=0.24 A \lambda_{0}
$$

where $\lambda_{0}$ is the free-space wavelength and $A$ is the length-to-radius parameter for the stub monopole given by 


$$
A=\frac{L / r}{1+L / r}
$$

where $L$ is the length and $r$ is the radius of the stub. For a conductor of non-circular cross-section, it is necessary only to take an equivalent radius, according to Hallen [5]. For a thin flat sheet of width, $L$, the equivalent radius is given by

$$
r=\frac{L}{2 \pi}
$$

and consequently,

$$
A=0.86
$$

for the square element. The frequency corresponding to the lower edge of the bandwidth, $f_{L}$, for the square monopole above a large groundplane can therefore be approximated by

$$
f_{L}(G \mathrm{~Hz})=\frac{61.9}{L}
$$

where $L$ is the side length in $\mathrm{mm}$. The measured and calculated lower edge frequencies are tabulated in Table 2. Results indicate the above formula to be accurate to within $\pm 8.5 \%$ for frequencies in the range $1 \mathrm{GHz}$ to $6 \mathrm{GHz}$.

TABLE 2 - Calculated and measured frequencies for the lower edge of the impedance bandwidth.

\begin{tabular}{|c|c|c|c|}
\hline $\begin{array}{c}\text { Side } \\
\text { length } \\
(\mathrm{mm})\end{array}$ & $\begin{array}{c}\text { Measured } \\
\text { value } \\
(\mathrm{MHz})\end{array}$ & $\begin{array}{c}\text { Calculated } \\
\text { value } \\
(\mathrm{MHz})\end{array}$ & $\begin{array}{c}\text { Error } \\
( \pm \%)\end{array}$ \\
\hline 55 & 1230 & 1125 & 8.5 \\
\hline 50 & 1340 & 1238 & 7.6 \\
\hline 45 & 1440 & 1375 & 4.5 \\
\hline 40 & 1590 & 1547 & 2.7 \\
\hline 35 & 1860 & 1768 & 4.9 \\
\hline 30 & 1980 & 2063 & 4.2 \\
\hline 25 & 2380 & 2476 & 4.0 \\
\hline
\end{tabular}

The effect of a change in width of the element can be used to tailor (increase or decrease) the bandwidth. Reducing the width of the element can significantly increase the impedance bandwidth (by up to $100 \%$ ), whereas increasing the width reduces the bandwidth.

\section{RADIATION PATTERN}

The $E$ and $H$ plane radiation patterns for the 30 $\mathrm{mm}$ element were measured at the centre frequency of $3.0 \mathrm{GHz}$ and are illustrated in figures $6 \mathrm{a}$ and $6 \mathrm{~b}$. The coordinate system used is shown in Figure 5. The antenna exhibits a quasiomnidirectional pattern in the $\mathrm{H}$-plane with a maximum variation of $\pm 1.5 \mathrm{~dB}$, and a typical monopolar pattern in the E-plane. The pattern variation with frequency is negligible over the impedance bandwidth.

The gain was found to be $1.5 \mathrm{dBi}$ in the plane of the groundplane but increased to a maximum of $4.5 \mathrm{dBi}$ at an elevation of 40 degrees with respect to the groundplane, yielding a conical beam pattern. This is typical of monopoles, with the beam tilt due to the finite groundplane effect [6]. The cross polarization was $15 \mathrm{~dB}$.

\section{CONCLUSION}

A broadband square monopole antenna has been investigated, showing a constant radiation pattern over the impedance bandwidth. A simple formula for the frequency corresponding to the lower edge of the impedance bandwidth, which has an accuracy of $\pm 8.5 \%$ over the frequency range 1 $\mathrm{GHz}$ to $6 \mathrm{GHz}$, is proposed. The effect of the feedgap distance is examined.

\section{REFERENCES}

1. Honda, S. et al. 1992, A disk monopole antenna with 1:8 impedance bandwidth and omnidirectional radiation pattern, Proc. ISAP, Sapporo, Japan, 1145-1148.

2. Hammoud M. et al., 1993, Matching the input impedance of a broadband disc monopole, Electronics Letters, 29, (4), 406-407.

3. Agrawall, P. A., Kumar, G. and Ray, K., 1998, Wideband planar monopole antennas, IEEE Trans. AP46, (2), 294-295.

4. Kraus, J., 1950, Antennas, McGraw Hill, London, 276. 
5. Hallen E., 1938, Theoretical investigations into the transmitting and receiving qualities of antennae, Nova Acta Regiae Soc. Sci. Upsaliensis, Sec. IV, 11, No. 4, $1-44$.

6. Hahn, R and Fikioris, J., 1973, Impedance and radiation pattern of antennas above flat discs, IEEE Trans., Antennas and Prop., January, 97-100

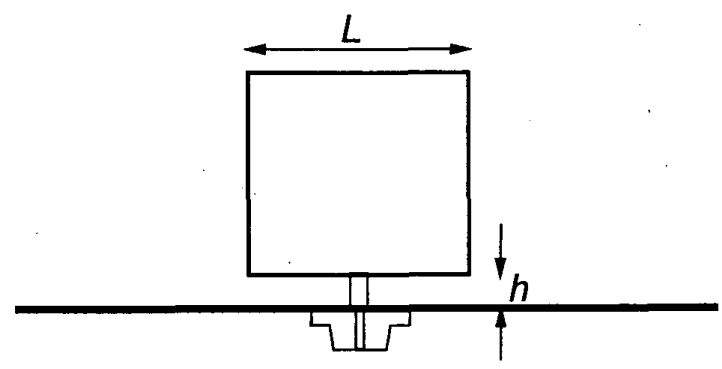

Figure 1. The square planar monopole above the groundplane

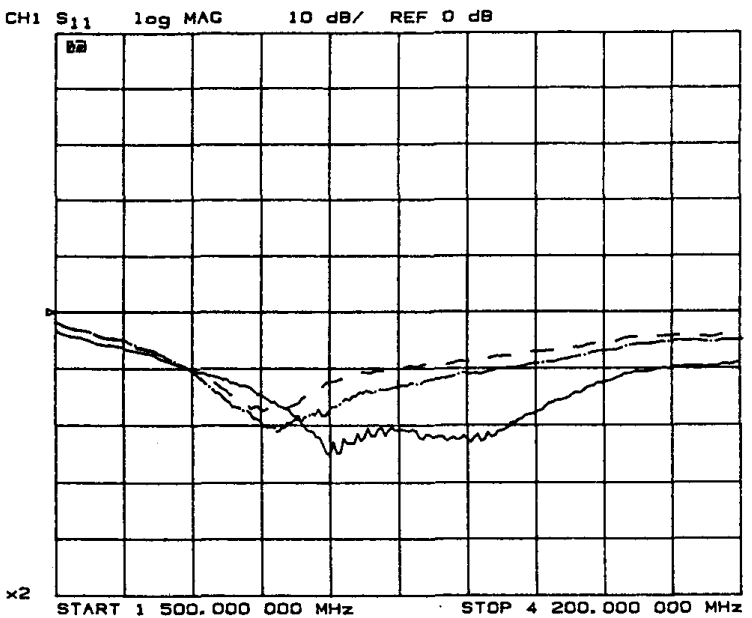

Figure 2. Swept return loss for the $30 \mathrm{~mm}$ element with feedgaps of $0.8 \mathrm{~mm}$ (dashed), $1.6 \mathrm{~mm}$ (dot-dashed) and 2.5 $\mathrm{mm}$ (solid).

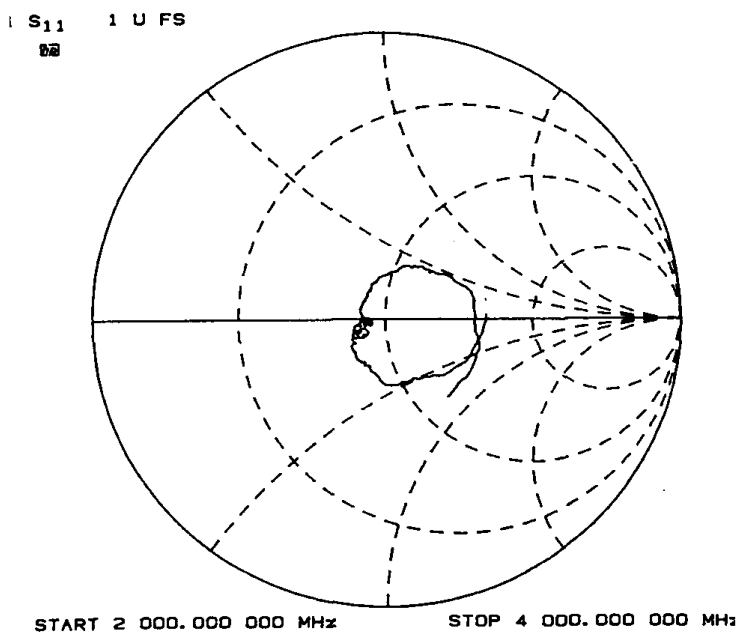

Figure 3. Swept impedance locus for the $30 \mathrm{~mm}$ square monopole from $2 \mathrm{GHz}$ to $6 \mathrm{GHz}$.

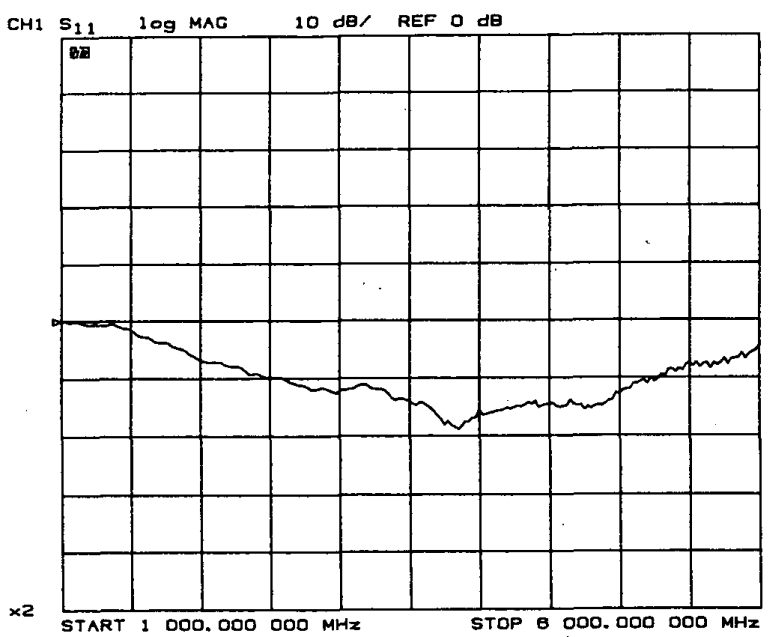

Figure 4. Swept return loss for the $25 \mathrm{~mm}$ element indicating an impedance bandwidth of $2.82 \mathrm{GHz}$. 


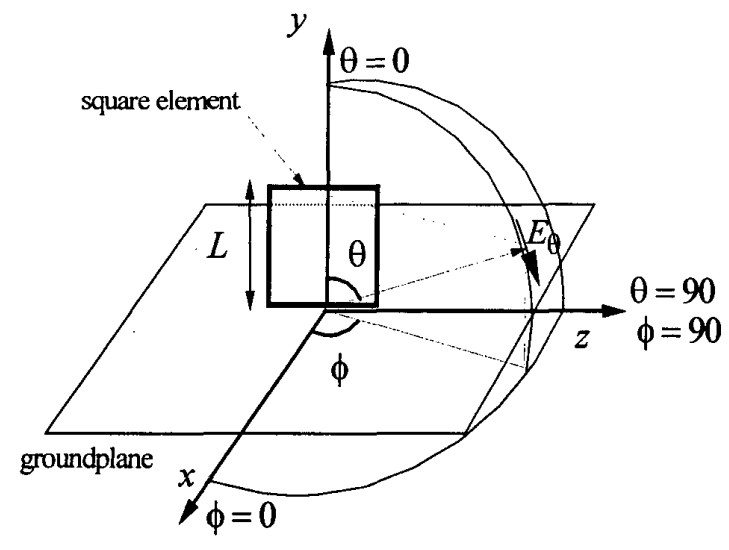

Figure 5. Coordinate system used for radiation pattern measurements. The square element lies in the $y z$ plane and the groundplane lies in the $x z$ plane.

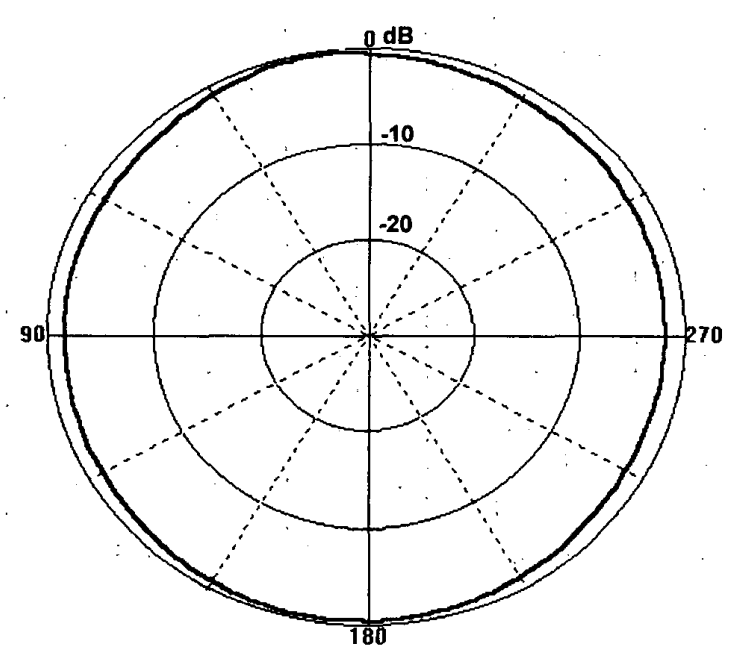

Figure $6 a$. Normalised $\mathrm{H}$-plane radiation pattern.

( $E_{\theta}$ in the plane $\theta=90$ )

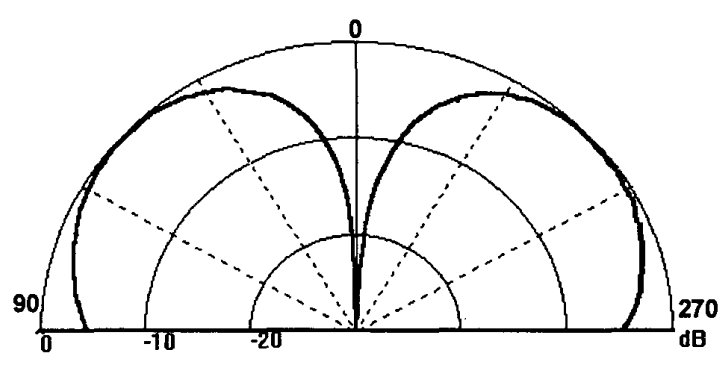

Figure 6b. Normalised E-plane radiation pattern ( $E_{\theta}$ in the plane $\phi=90$ ) 